\title{
SEISMIC RESPONSE EVALUATION OF BUILDING WITH VISCOUS AND VISCOELASTIC DAMPERS
}

\author{
Ganesh P Gadakh ${ }^{1}$, Rajashekhar S. Talikoti \\ ${ }^{I} P G$ Student, Late G. N. Sapkal College of Engineering,Nashik,Maharashtra, India \\ ${ }^{2}$ Head of Department, Late G. N. Sapkal College of Engineering, Nashik, Maharashtra, India
}

\begin{abstract}
There is a great need for implementation of various earthquake mitigation techniques for effective control over the earthquake. The energy dissipation devices for dissipating earthquake energy needs to be studied in depth from view point of their efficiency in resisting earthquake forces. In this paper the performance of viscous and viscoelastic dampers are studied in detail. The seismic performances of these dampers are compared with normal bare frame building. Nonlinear modal time history analysis using Elcentro time history data was performed and parameters such as base shear, displacement time history at roof level, modal time period and maximum forces in outer and inner column are compared and presented. The modelling and analysis of building is done using SAP analysis package. The viscous and viscoelastic dampers are modeled by using nonlinear link element having property type dampers. The viscoelastic dampers are modeled as per Maxwell model of viscoelasticity. The properties of viscous dampers are calculated from shear storage modulus and shear loss modulus. The results obtained from analysis indicate efficient performance of viscous damper for resistance against maximum forces and control over displacement and base shear
\end{abstract}

Keywords: Viscous Damper, Viscoelastic Damper, Nonlinear Time History, SAP.

\section{INTRODUCTION}

In view of earthquake mitigation the three major classifications are Base isolation, Active energy dissipation devices and Passive energy dissipation devices. All energy dissipation devices basically perform the same role of converting mechanical energy from external load to head energy. An isolation system absorbs the energy and filters the motion before it passes in to the structure where as in structure damping dissipates energy depending on the characteristics of each of the components i.e., structural system and devices. Damping is a conversion of mechanical energy in to a thermal energy. The amount of energy dissipated is a measure of structures damping level. Damping is very important since it dissipate the destructive energy of earthquake which will ultimately help to reduce the damage to the building. Damping is the decrease in amplitude with time due to the resistance of medium to vibration. Damping always occurs progressively since energy is taken out of the system by another force called friction. If the damping is enough that the system is just fails to oscillate then it is said to be critically damped. The damping more than this is called as over damped and less than this is called as under damped.

\section{METHODOLOGY}

In the present paper two different types of dampers are selected for the study namely viscous and viscoelastic dampers. The seismic performances of these dampers are compared with normal bare frame building without any energy dissipation devices. G+15 building is selected for the study. Following three types of models are considered. In the model with damper the location of damper is kept same only type of damper is changed

Model CM: Bare frame building without energy dissipation devices. This model will act as a control model Model D1: Bare frame building with viscoelastic dampers Model D2: Bare frame building with viscous damper Seismic and other data used for the study is shown in Table I below. The preliminary design is performed using combinations used for limit state of strength and serviceability. After fixing sizes of various members nonlinear modal time history analysis was performed for time history record of Elcentro earthquake. The structural plan of building with location of dampers are shown in Fig.1 below

Table-1: Data used for Analysis

\begin{tabular}{|l|l|}
\hline Response reduction factor & 5 \\
Importance factor & 1.5 \\
Soil condition & Medium \\
External wall & $230 \mathrm{~mm}$ \\
Internal wall & $115 \mathrm{~m}$ \\
Thickness of shear wall & $200 \mathrm{~mm}$ \\
Unit weight of Brick masonry & $18 \mathrm{KN} / \mathrm{m}^{3}$ \\
Unit weight of RC & \\
Thickness of slab & $25 \mathrm{KN} / \mathrm{m}^{3}$ \\
Floor to floor height & $150 \mathrm{~mm}$ \\
Grade of steel & $3.2 \mathrm{~m}$ \\
Grade of concrete & Fe 500 \\
Floor finish & $\mathrm{M} 30$ \\
Live load & $1.5 \mathrm{KN} / \mathrm{m}^{2}$ \\
Height of parapet wall & $3.0 \mathrm{KN} / \mathrm{m}^{2}$ \\
Type of frame & $1 \mathrm{~m}$ \\
& $\mathrm{SMRF}$ \\
\hline
\end{tabular}




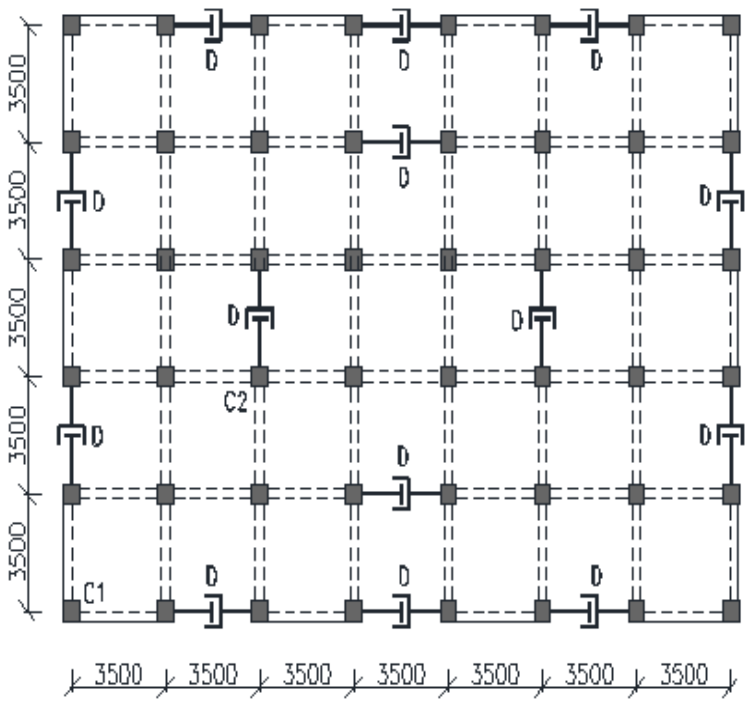

Fig- 1: Structural plan showing location of damper (Model D1 and M2)

\section{MODELLING AND ANALYSIS}

The Building is modeled by using SAP 16. Beams and columns are modeled as two nodded line element with six DOF at each node. Slab is modeled as four nodded membrane element with six DOF at each node. The viscous and viscoelastic dampers are modeled by using nonlinear link element having property type dampers. The link elements have six DOF at each node. The viscoelastic dampers are modeled as per Maxwell model of viscoelasticity. The properties of viscoelastic dampers are calculated from shear storage modulus and shear loss modulus. The mathematical for the building is shown in Fig.2

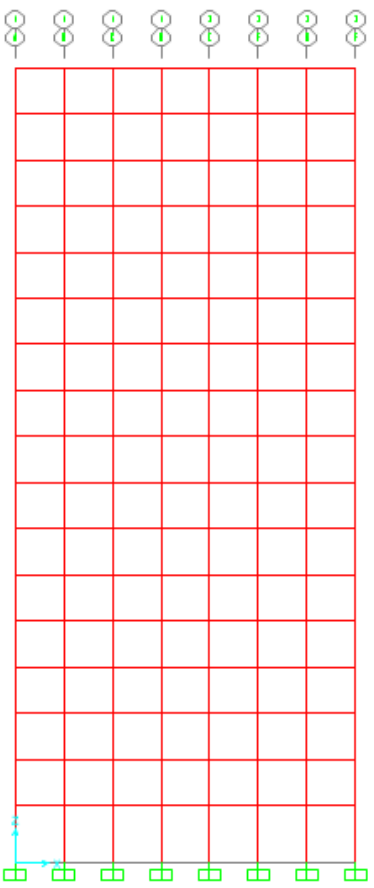

(a) Model CM

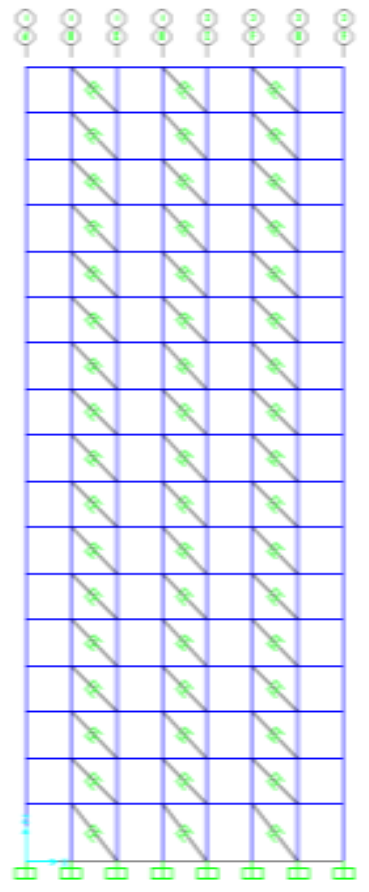

(b) Model D1 and D2
Fig- 2: Mathematical Models
Table-1: Details of Time History Dada

\begin{tabular}{|l|l|}
\hline Earthquake & El Centro \\
\hline Date \& time & $18 / 05 / 1940$ \\
\hline Station & Imperial Valley \\
\hline Hypocentral distance & $12.12 \mathrm{Km}$ \\
\hline Earthquakecomponunt & $\mathrm{N} 75 \mathrm{E}$ \\
\hline Peak acceleration & $341.69 \mathrm{~cm} / \mathrm{s} / \mathrm{s}$ \\
\hline No of acceleration data & 1559 \\
\hline Unit & $\mathrm{g}$ \\
\hline Time interval & $\mathrm{NA}$ \\
\hline Magnitude & 6.9 \\
\hline Scale factor for SAP & 9.81 \\
\hline
\end{tabular}

\section{RESULTS AND DISCUSSION}

The results obtained from the analysis are presented in terms of response quantities such as displacement, base shear and maximum forces in columns for the two principal directions.

\subsection{Base shear}

The base shear variation for different time interval are plotted for different models and presented in Fig. 3 and Fig.4 Reduced response was observed for model D1 and D2, however the least base shear was found in model D2 (Viscous damper). The viscous damper is found to be very effective as far as base shear is concern.

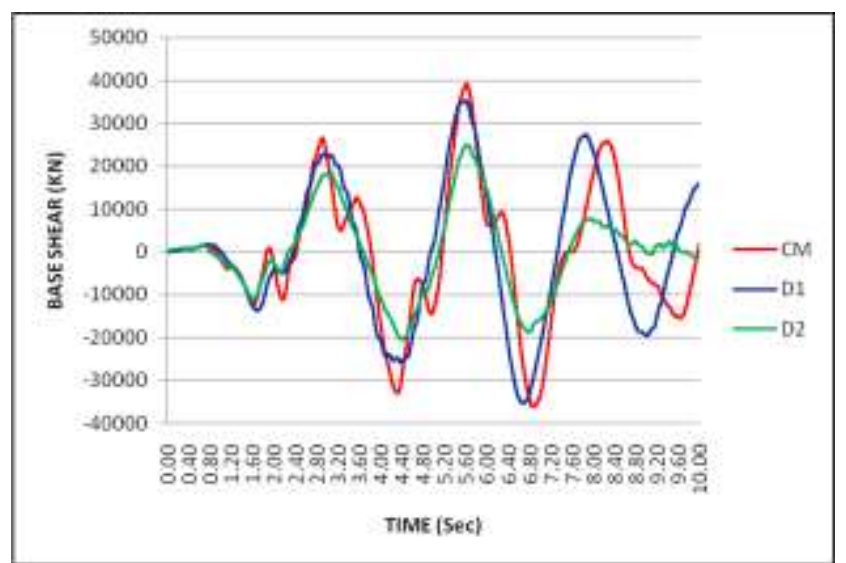

Fig- 3: Time history of base shear variation along $X$

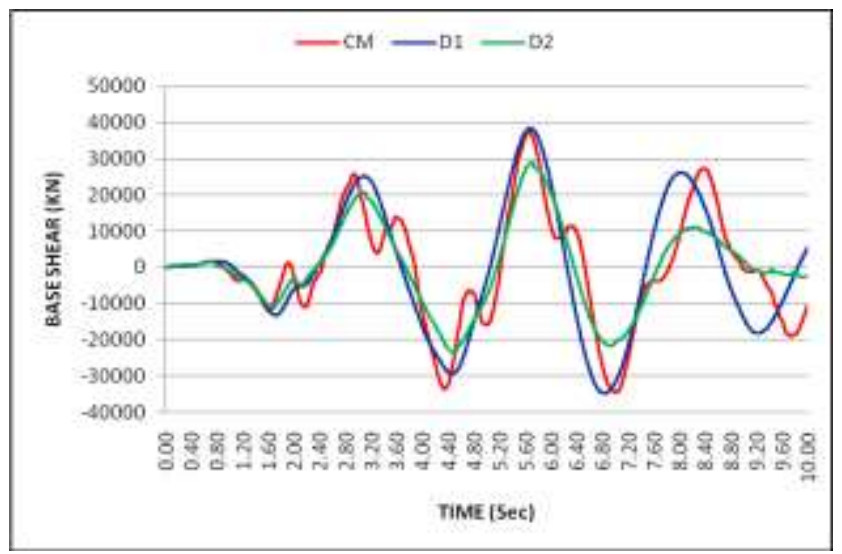

Fig- 4: Time history of base shear variation along Y 


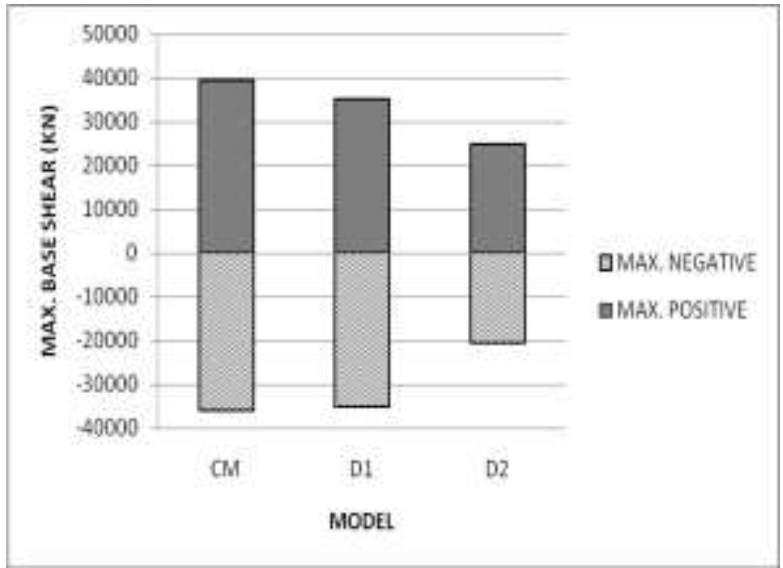

Fig- 5: Maximum base shear along $X$

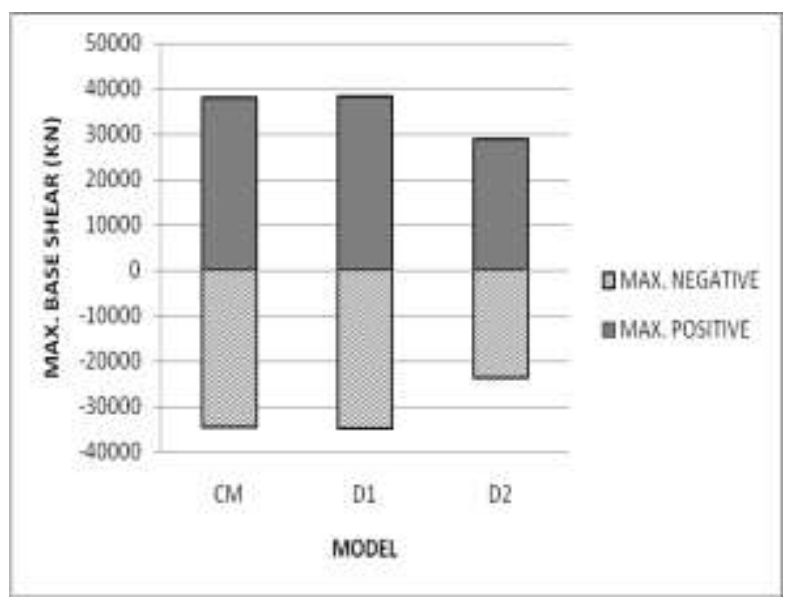

Fig- 6: Maximum base shear along Y

\subsection{Displacement}

Time history of roof displacement is presented below. The displacement is found to be minimum along both the principal direction for model D2( Model with viscous damper)

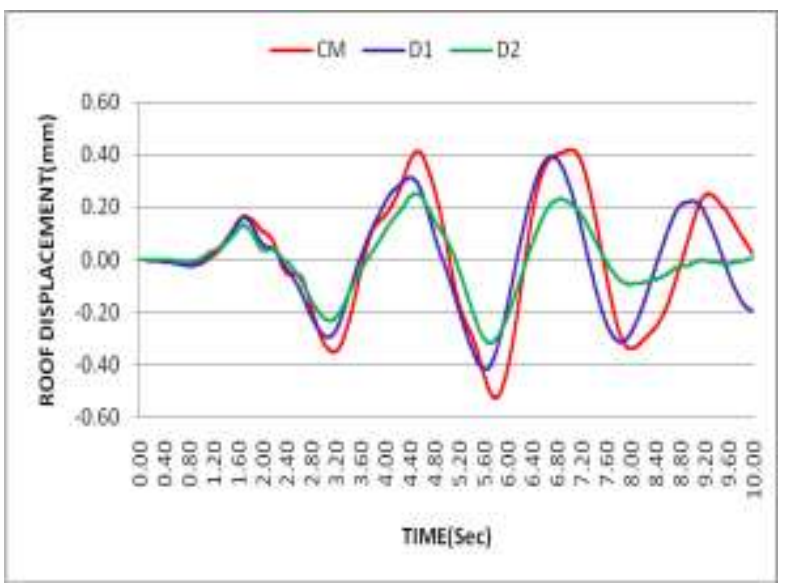

Fig- 7: Time history of roof displacement along X

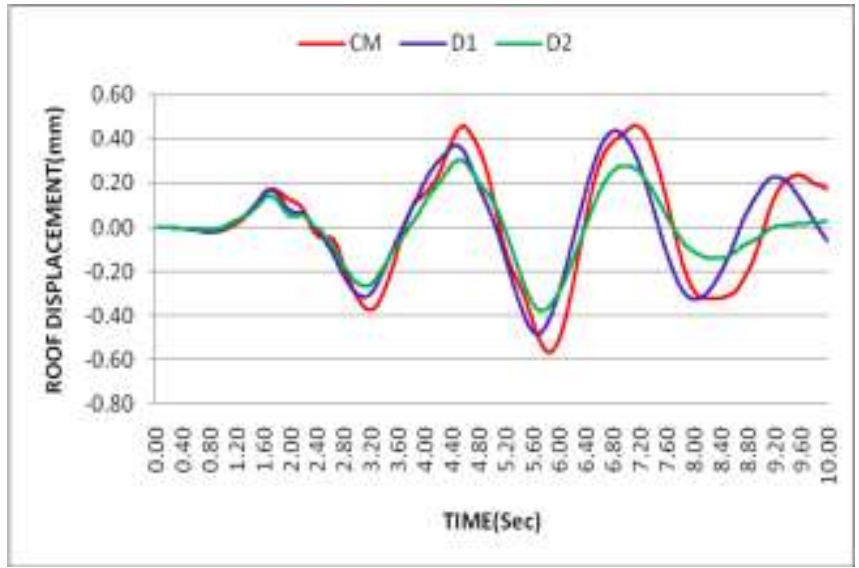

Fig- 8: Time history of roof displacement along Y

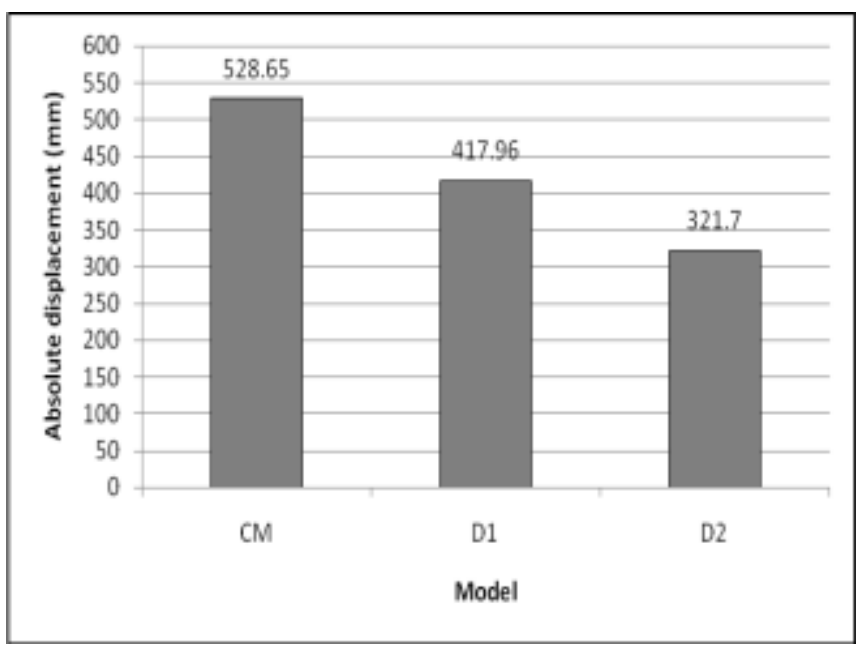

Fig- 9: Absolute maximum displacement along $X$

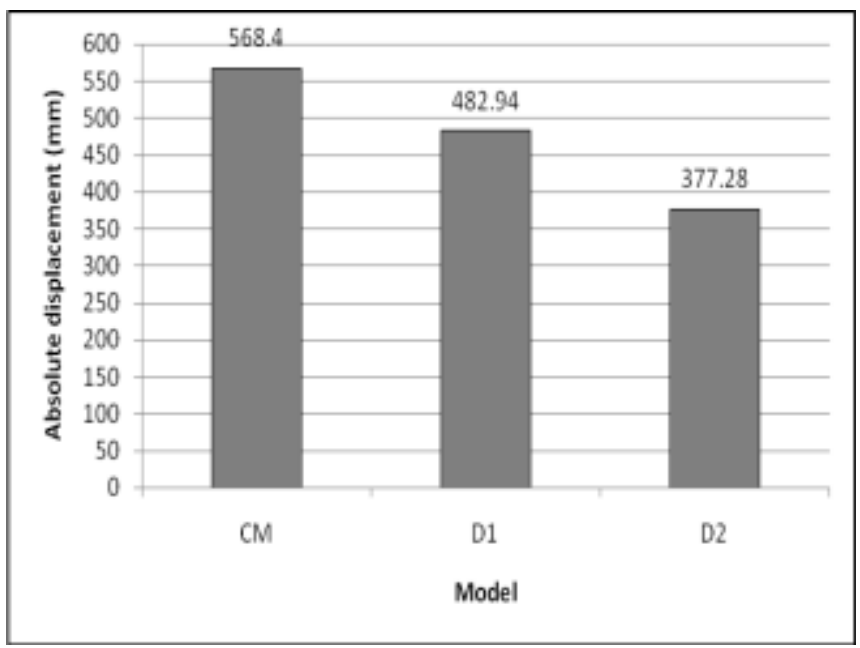

Fig- 10: Absolute maximum displacement along $\mathrm{Y}$

\subsection{Maximum Forces in Columns}

To judge exact behaviour of building with damper, two columns are selected ie $\mathrm{C} 1$ and $\mathrm{C} 2$ as shown in Fig. 1 above. The column $\mathrm{C} 1$ is an exterior column and column $\mathrm{C} 2$ is an interior column. 


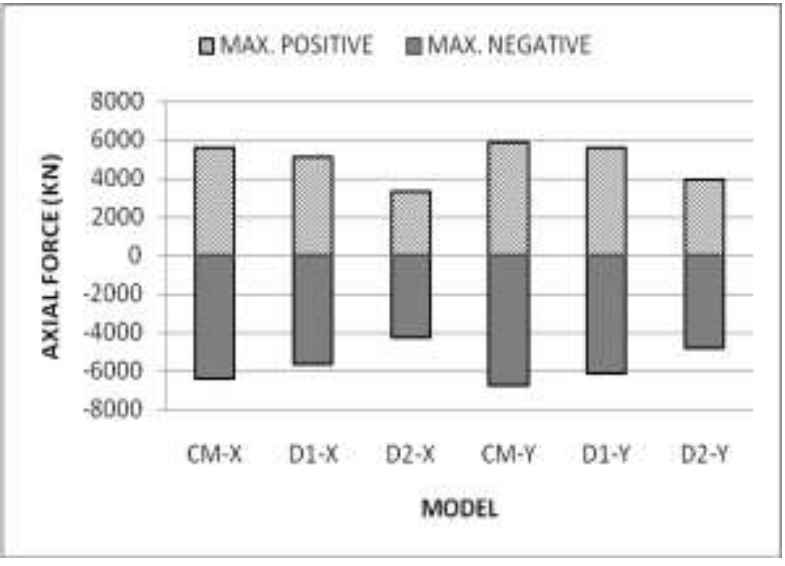

Fig- 11: Maximum Axial force in Column C1

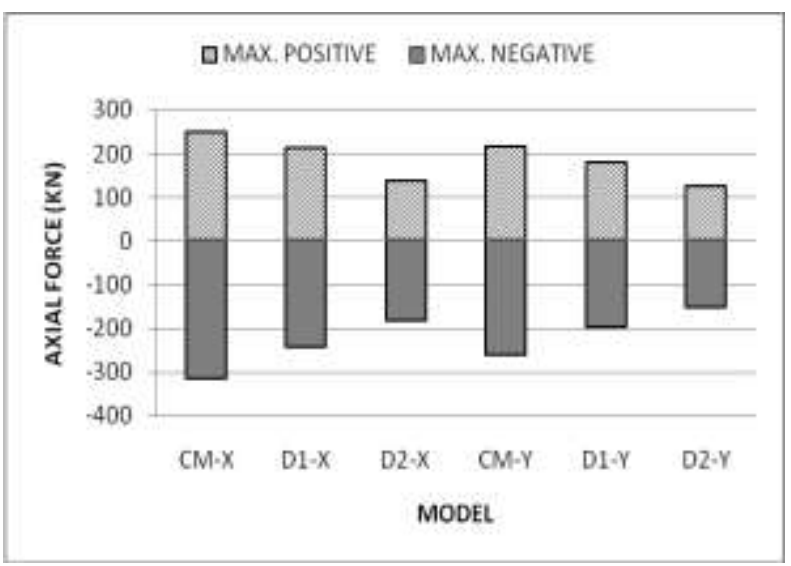

Fig- 12: Maximum Axial force in column C2

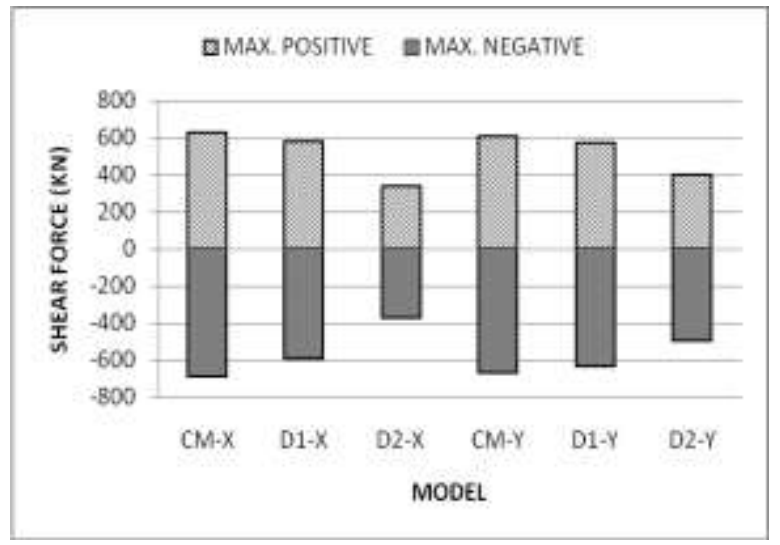

Fig- 13: Maximum Shear force in column C1

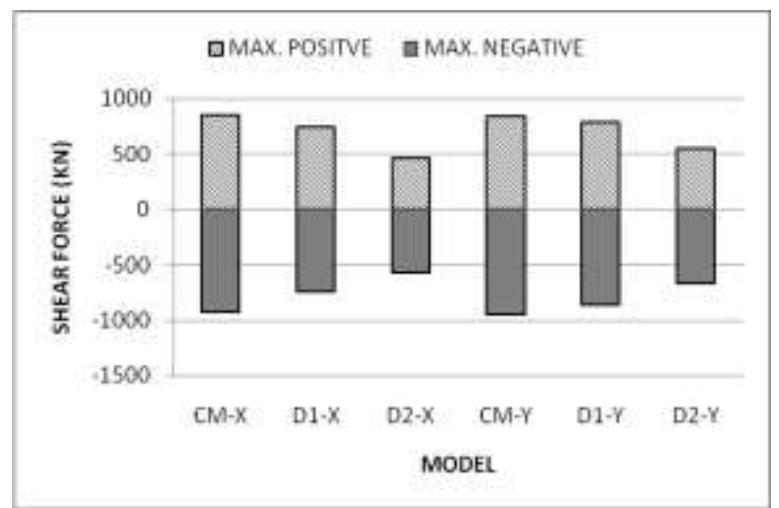

Fig- 14: Maximum Shear force in column C2

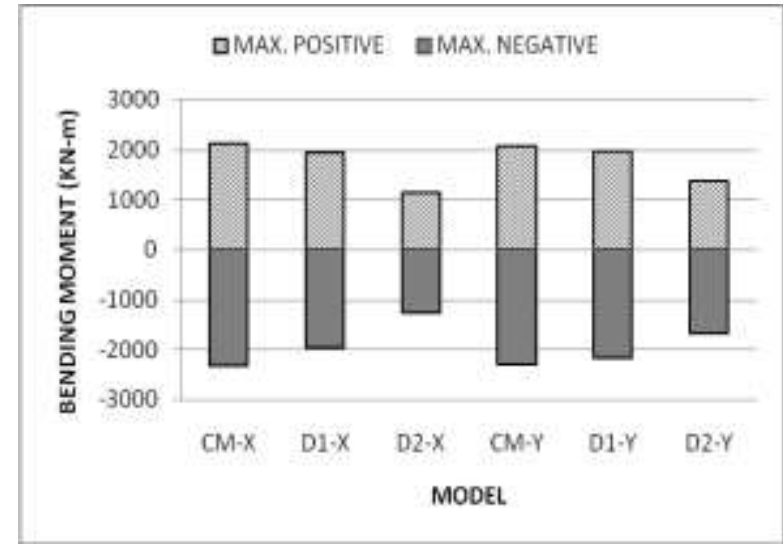

Fig- 15: Maximum bending moment in column $\mathrm{C} 1$

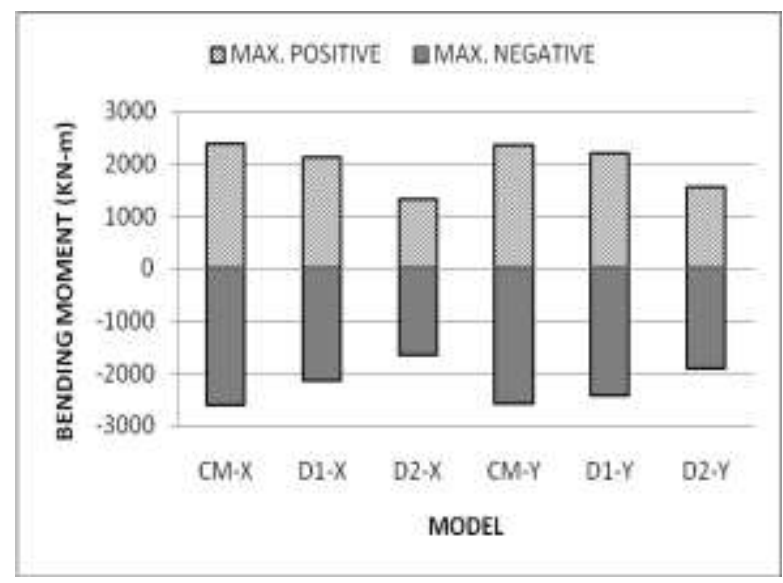

Fig- 16: Maximum bending moment in column $\mathrm{C} 2$

The axial force is found to be maximum in model CM where as minimum in model D2. There is about $58 \%$ reduction in axial force was observed in model D2 as compared to model CM. The axial forces are more in exterior columns as compared to interior columns. The axial forces are minimum for buildings with viscous dampers.

\section{CONCLUSION}

It is concluded from the results obtained that the performance of viscous damper is much better than the viscoelastic damper. The displacement and base shear is found to be minimum for viscous damper. Along $\mathrm{X}$ direction the base shear for model with viscous damper was $36.8 \%$ less than the control model and $31.03 \%$ less as compared to model with viscoelastic damper. The shear force and bending moment in columns are found to be minimum in model D2 (model with viscous damper). There is not much variation in shear force and bending moment was observed between interior and exterior columns. The shear force in model D2 was $51.2 \%$ less than shear force in model CM where as there is $53.7 \%$ reduction in bending moment was observed.

\section{REFERENCES}

[1] K yung-Won MIn, "Vibration test of 5-storey steel frame with viscoelastic dampers," Engineering Structures 26 (2004) 831-839 
[2] M.P. Singh" Seismic analysis of structures with viscoelastic dampers." Journal of Engineering Mechanics-ASCE-2009,1356(6), 571-580

[3] Ri Hui Zhang, "Seismic Design of Viscoelastic dampers for Structural Applications," Journal of structural Engineering-ASCE, 1992, 118(5):1375-1392

[4] C.S.Tsai, "Application of Viscoelastic dampers to high rise buildings," Journal of structural EngineeringASCE, 1993, 119(4):1222-1233

[5] Nicos Makris, "Analytical model of viscoelastic Fluid dampers," Journal of structural EngineeringASCE, 1993, 119(11):3310-3325

[6] C.S.Tsai, "Temperature effect of viscoelastic damper during Earthquake," Journal of structural EngineeringASCE, 1994, 120(2):394-409

[7] Yaomin Fu, "Comparative study of Frame using Viscoelastic and Viscous dampers," Journal of structural Engineering-ASCE,1998, 124(5):513-522

\section{BIOGRAPHIES}

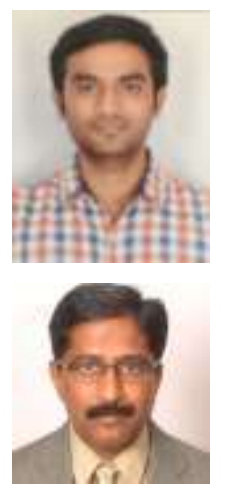

Ganesh Pundlik Gadakh, PG Student, Late G. N. Sapkal College of Engineering Nashik, Maharashtra, India

E-mail: ganeshgadakh14@gmail.com

Dr. Rajashekhar S. Talikoti, Head of Department, Late G. N. Sapkal College of Engineering, Nashik, Maharashtra, India E-mail: rstalikoti@gmail.com 